\title{
Erratum to: The transition from the present-day climate to a modern Snowball Earth
}

\author{
Aiko Voigt · Jochem Marotzke
}

Published online: 26 April 2011

(C) Springer-Verlag 2011

Erratum to: Clim Dyn (2010) 35:887-905

DOI 10.1007/s00382-009-0633-5

Unfortunately, in the aforementioned contribution, we listed incorrect albedo values for bare and snow-covered sea ice at $0^{\circ} \mathrm{C}$. The correct values that have been used in the model simulations are 0.55 for bare sea ice (instead of 0.5 ), and 0.65 for snow-covered sea ice (instead of 0.6). Please note that the sea-ice albedo values for temperatures at or below $-1^{\circ} \mathrm{C}$, as well as the albedo values for snow on land, are given correctly in the aforementioned contribution.

The online version of the original article can be found under doi:10.1007/s00382-009-0633-5.

\footnotetext{
A. Voigt $(\bowtie)$ Modelling, Bundesstrasse 53, 20146 Hamburg, Germany

e-mail: aiko.voigt@zmaw.de

A. Voigt - J. Marotzke

Max Planck Institute for Meteorology,

Bundesstrasse 53, 20146 Hamburg, Germany

e-mail: jochem.marotzke@zmaw.de
}

International Max Planck Research School on Earth System, 